\title{
Eu hei-de amar uma pedra: dimensão dialógica entre imagem e escrita
}

Dalva Calvão

Universidade Federal Fluminense

Em miúdo, conheci pessoas rodeadas de fotografias antigas. Perguntava quem eram aquelas pessoas diziam-me ser o trisavô, todas pessoas mortas. Eu pensava: como podem estar mortas se olham para mim desta maneira, como se me conhecessem? Tinha a sensação de que as pessoas daquelas fotografias me compreendiam melhor do queas vivas. Naquelas fotografias amarelas subsistia a vida, o olhar. Na capacidade de transmissão de emoções e vivências, a fotografia sempre me fascinou.

António Lobo Antunes ${ }^{1}$

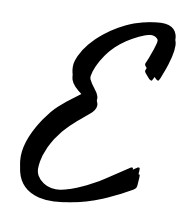

$u$ hei-de amar uma pedra (2004) é um longo romance dividido em quatro partes - "As fotografias", "As consultas", "As visitas", "As narrativas" -, sendo que cada uma delas se subdivide em vários capítulos. O núcleo temático que costura todas essas partes e capítulos é a história de uma insólita e frustrada relação amorosa, iniciada timidamente na juventude de um modesto casal, e retomada muitos anos depois. Supondo que sua amada havia morrido em um sanatório, o rapaz se casa com outra, com quem tem duas filhas, e somente muitos anos depois, ao

${ }^{1}$ ARNAUT, 2008, p. 455. 
encontrar casualmente a antiga namorada, revive, numa acanhada pensão do Bairro da Graça, ao longo de cinqüenta anos, o sonho de sua juventude, transformado em melancólica e clandestina história de amor proibido e, ao que tudo indica, platônico. Além dos encontros semanais na pensão, o casal se permitia raros passeios a Sintra e, à distância, se via na praia, em Tavira, pontualmente nas férias de verão, quando a amante, sempre em silêncio e em total discrição, ocupada com um eterno crochê em sua cadeira de lona, fingia-se alheia aos movimentos da família do homem, também aparentemente indiferente à sua existência e presença. Segundo Lobo Antunes, este enredo se origina da história real de uma paciente idosa, de que ele tomou conhecimento no hospital onde exercera sua atividade de médico psiquiatra. ${ }^{2}$ Desta suposta parcela de realidade, ele constrói um labiríntico universo ficcional, em que, ao casal central, juntam-se muitas outras personagens, todas envolvidas em suas respectivas e complexas intrigas, a representarem, na permanência de marcas próprias às narrativas do autor, o imensurável desconcerto das experiências humanas, de modo particular, as angústias provenientes dos amores mal resolvidos, das relações familiares desgastadas ou falsas, da incomunicabilidade, da solidão e das perdas.

Na primeira parte do romance, a voz do narrador principal - o marido, pai e amante -, alterna-se com as vozes das filhas e do genro, sem mencionarmos algumas intromissões de falas da esposa, da amante e de outras personagens, numa composição já conhecida dos leitores de Lobo Antunes, em que fluxos de consciência se misturam sem que os limites claros entre eles sejam evidenciados: tem-se, por isto, muitas vezes, a impressão de que um narrador pensa ou inventa o que seriam as falas de outras personagens, disto resultando um tecido verbal ao mesmo tempo vertiginoso e fragmentário. O ponto de partida de

2 ARNAUT, 2008, p. 464-465. 
todos esses discursos é um antigo álbum de fotografias, de onde foram destacadas dez fotos (correspondentes aos dez capítulos dessa primeira parte), de cuja observação derivam todas as reflexões dos narradores: de três delas se ocupam o genro e as filhas e as outras sete são minuciosamente observadas pelo pai que, no presente de sua narrativa, é já um velho a remoer acontecimentos do passado, recuperando, afinal numa ordem cronológica, apesar do discurso intensamente móvel e muitas vezes aparentemente desestruturado, as principais fases de sua vida (a única ordem, na verdade, é a da disposição das fotos no álbum, o que dá ao leitor uma certa organização temporal que, na voz do narrador, perde-se, bifurcando-se em vários tempos sobrepostos). Tomamos, assim, conhecimento de sua infância pobre com a mãe, do abandono do pai, da presença do Primo Casimiro - suposto amante da mãe -, da sua participação na guerra colonial, na Guiné, do seu casamento, das filhas, das férias na praia, da existência da amante e de muitos outros fatos e personagens, valendo observar que nem todos aparecem nas fotografias, mas surgem em decorrência de associações de ideias originadas da observação das mesmas e das evocações do passado. Nesta direção, para este narrador, as fotografias de seu álbum parecem se configurar, proustianamente, como detonadoras da memória, como vestígios e pistas que dão acesso ao território do tempo perdido. Esta seria, talvez, a interpretação que mais prontamente ocorreria ao leitor do romance, embora a questão possa se colocar de outra forma: se tomarmos, por exemplo, como referência o estudo de Roland Barthes sobre a fotografia, podemos ler de outra forma a relação do narrador com as imagens de seu passado e afirmar que "a fotografia não rememora o passado (não há nada de proustiano em uma foto)", 3

${ }^{3}$ BARTHES, 1984, p. 123. 
isto porque o efeito produzido pela foto "não é o de restituir o que é abolido (pelo tempo, pela distância), mas o de atestar que o que vejo de fato existiu" ${ }^{4}$ Ou seja, a fotografia não recupera, fantasmaticamente, o passado: ela é o passado, é a evidência de que aquilo existiu, sendo esta "aderência" do referente, ${ }^{5}$ a própria especificidade da fotografia:

Chamo de 'referente fotográfico' não a coisa facultativamente real que remete a uma imagem ou um signo, mas a coisa necessariamente real que foi colocada diante da objetiva, sem a qual não haveria fotografia. A pintura pode simular a realidade sem tê-la visto. $\mathrm{O}$ discurso combina signos que certamente têm referentes, mas esses referentes podem ser e na maioria das vezes são "quimeras". Ao contrário dessas imitações, na Fotografia jamais posso negar que a coisa esteve lá. Há dupla posição conjunta: de realidade e de passado. ${ }^{6}$

Neste sentido, para o narrador em destaque, as fotos eleitas teriam, em primeiro lugar, o papel de, objetivamente, confrontálo com seu passado, o qual se lhe apresenta não como nebulosa possibilidade, mas como força de evidência: tudo aquilo que ele vê, em princípio, de fato, existiu. Este contato com o real de seu passado, contudo, não será uma experiência pacífica: a objetividade do real configurada pelas fotos não impedirá a violência das emoções despertadas, nem a possibilidade, a partir dessa mesma exposição do fato passado, da digressão imaginária por labirínticos espaços da subjetividade: pelo contrário, diante do real passado, o narrador parece se alinhar na atitude descrita, no mesmo estudo, por Barthes, como resultante do impacto causado por algum elemento da foto sobre o expectador, algo que

\footnotetext{
${ }^{4}$ BARTHES, 1984, p. 123.

${ }^{5}$ BARTHES, 1984, p. 16.

${ }^{6}$ BARTHES, 1984, p. 114-115.
} 
"parte da cena, como uma flecha, e vem me transpassar", 7 aquilo a que o estudioso francês denomina punctum, palavra latina que designa "essa ferida, essa marca feita por um instrumento pontudo": " "pois punctum é também picada, pequeno buraco, pequena mancha, pequeno corte - e também lance de dados. $\mathrm{O}$ punctum de uma foto é esse acaso que, nela, me punge (mas também me mortifica, me fere)". 9

E será assim, mortificado e ferido, que a personagem acompanhará as imagens que pontuam seu trajeto existencial, tomando, quase sempre, num primeiro momento, a foto em sua totalidade, toda ela a transpassá-lo como uma flecha, como um ponto cortante, abrindo, a partir deste corte, o espaço para uma interminável ruminação de ideias, no qual formulações do imaginário e do hipotético se produzem de forma às vezes delirante. $\mathrm{O}$ vivido e o imaginado confundem-se e o que foi perdido reaparece, agora, sim, num exercício de memória desvinculado da presença física da imagem estampada no álbum $\mathrm{e}$, frequentemente, com força mais acentuada do que a que emana da foto presentificada. Assim é, de forma emblemática, com a foto da antiga namorada, oferecida a ele nos tempos da adolescência e cautelosamente retirada do álbum. Esta foto ausente presentificase nostalgicamente na memória do narrador, a persegui-lo como um moto contínuo, de que ele, afinal, não deseja se libertar:

mas não foi o retrato da minha mãe que tirei com o canivete do álbum [...] a imagem de uma menina em roupa de comunhão solene, o crucifixo, as mãos postas, sem cenário por trás [...] uma mesa de pé de galo com uma bailarina no tampo, a justificação aflita

\footnotetext{
${ }^{7}$ BARTHES, 1984, p. 46.

${ }^{8}$ BARTHES, 1984, p. 46.

${ }^{9}$ BARTHES, 1984, p. 46.
} 
- Não tenho outra desculpe [...]

a mesa de pé-de-galo importantíssima, no exacto centro da sala, dava-se corda à bailarina

(- Podia dar-se corda à bailarina sabia?)

e ela a rodopiar empenada detendo-se no primeiro ressalto, com um toquezinho na base estremecia num pulo, entortava-se mais, continuava a girar [...]

voar através da África, de Tavira, ao encontro de uma bailarina vestida de comunhão solene (- Pode dar-me corda sabia?) $)^{10}$

Memória e imaginação acabam, assim, por fundir, numa mesma imagem, a menina e a bailarina de corda, esta, sim, o verdadeiro ponto de atração dessa foto evocada, configurando-se como o detalhe barthesiano que domina a visão do espectador "Esse 'detalhe' é o punctum (o que me punge)"11 - e certamente não por acaso: como uma boneca de corda, a amante terá, mais tarde, seus movimentos dependentes do comando do homem, agindo (dançando?) de acordo com sua vontade, imobilizando-se em silêncio segundo suas conveniências: "não o mandei embora, estou aqui, hei-de voltar todas as quartas-feiras consigo, vejo o retrato de suas filhas, oiço-o" $\left[\right.$...]. . $^{12}$

Parece-nos, pois, que, na passagem mencionada acima e em outras inúmeras situações, podemos considerar que as fotografias, no romance, serão responsáveis, mais do que pelo registro ou evidência do passado, pelo acionamento da máquina mental geradora de outras imagens, aquelas que avançam pelos espaços sombrios da interioridade, sem exigência da clareza do pensamento lógico: assim como a amante e a bailarina se fundem, muitas outras imagens se constroem, na mistura de um

\footnotetext{
${ }^{10}$ ANTUNES, 2004, p. 58, 63, 69.

11 BARTHES, 1984, p. 68.

12 ANTUNES, 2004, p. 104 e 112.
} 
acontecimento passado (registrado na foto) com retalhos de outros níveis do passado e com construções oníricas da imaginação, como acontece, por exemplo, com episódios traumáticos da guerra aproximados de situações e personagens da infância do narrador, o que abre sempre ao leitor desafiadoras possibilidades de interpretação:

Nessa fotografia demasiado pequena, demasiado turva, feita durante a guerra em Bissau [...]

sou o oitavo a contar da esquerda diante do muro do quartel [...]

e nem quartel talvez, veio um morteiro e sobram as folhas das árvores e os ditongos dos pássaros, o dono de um dos quintais do Beato estudava a horta, zangava-se, trazia a espingarda de chumbinhos e erguia do chão cartuchitos de penas ensanguentadas, sem cabeça

(nós)

esmagava-os vingado

- Já não me estragam as alfaces agora [...]

a fotografia em silêncio, nada, salvo os murmúrios do cacimbo ou do Tejo, mas o que era o Tejo em África senão umas canoas, umas ervas, a espingarda de chumbinhos na arrecadação, coisas sem importância alguma

(e por não terem importância alguma as recordo tão bem) como por exemplo a minha mãe quando o médico lhe devolveu as radiografias e chamou outro doente $[\ldots]^{13}$

O narrador parece, desta forma, lidar com dois regimes diferentes de imagens, aquelas que se lhe oferecem concretamente ao olhar e as que sua imaginação produz, ampliando interminavelmente as potencialidades de ambos os regimes e, de toda forma, transformando sempre as imagens em palavras, revelando a seu modo as duas formas de processos imaginativos de que nos

${ }^{13}$ ANTUNES, 2004, p. 51-52. 
fala Ítalo Calvino: "Podemos distinguir dois tipos de processos imaginativos: o que parte da palavra para chegar à imagem visiva e o que parte da imagem visiva para chegar à expressão verbal."14 No caso do narrador em questão, a segunda opção é o seu primeiro movimento: toda sua elocubração mental parte, primeiramente, de uma imagem visiva - uma fotografia - e, em seguida, através do fluxo mental que se forma, ele passa a criar novas imagens, corporificando-as através das palavras.

Convém, a esta altura, lembrar que o processo imaginativo que o protocolo da ficção nos permite atribuir ao narrador personagem é, em última instância, uma descrição do processo imaginativo do autor Lobo Antunes que, por estratégias de seu ofício, o transfere para sua criatura: mas, na verdade, sabemos que é de Lobo Antunes a inquestionável capacidade de descrever e de gerar imagens em seu poderoso jorro verbal: descrever a partir de supostos referentes concretos, gerar a partir da própria imaginação: os dois procedimentos mencionados por Calvino fazem parte da criação de Lobo Antunes (como, de resto, parecem fazer parte dos processos de criação literária de modo geral, apenas mais acintosamente intensificados em alguns autores e, em Lobo Antunes, de forma particular). Porém, diante do material escrito que, afinal, é o que nos chega às mãos, obviamente não poderemos nunca conferir a existência dos referentes concretos que deram origem aos exercícios mentais geradores da ficção. Em relação a este romance, sabemos superficialmente da existência de uma mulher que teria dado origem a todo o enredo. Quanto ao mais, tudo parece elaboração imaginária, a começar pelas fotografias que, na análise do romance, tomamos como referentes em que se baseia a voz do narrador, sem que possamos, no entanto, esquecer de que se trata de referentes ilusórios, tão fictícios quanto tudo o

${ }^{14}$ CALVINO,1990, p. 99. 
mais no livro, todas elas resultantes do imaginário do próprio autor. Comentando procedimentos da imaginação de Dante, na Divina Comédia, Calvino observa:

Dante está falando das visões que se apresentam a ele (ao personagem Dante) quase como projeções cinematográficas ou recepções televisivas num visor separado daquela que para ele é a realidade objetiva de sua viagem ultraterrena. Mas para o poeta Dante, toda a viagem do personagem Dante é como essas visões; o poeta deve imaginar visualmente tanto o que seu personagem vê, quanto aquilo que acredita ver, ou que está sonhando, ou que recorda, ou que vê representado, ou que lhe é contado, assim como deve imaginar o conteúdo visual das metáforas de que se serve precisamente para facilitar essa evocação visiva. ${ }^{15}$

É, portanto, desta prática tão antiga que, sobretudo, nos fala o romance de Lobo Antunes, deste poder da imaginação que funda a ficção, deste desdobramento das visões do autor na das personagens, enfim, da condição ilusória, porque imaginária, do texto literário. Neste sentido (ou seja, daquilo que, por trás do enredo, nos fala o livro: de seu próprio estatuto), será produtivo nos lembrarmos da composição de algumas das fotos descritas pelo narrador, nas quais a realidade supostamente comprovada da figura fotografada altera-se mediante a colocação, pelo fotógrafo, de painéis ou cenários - nos quais figuram paisagens pintadas, logo, inexistentes -, em alguns dos quais bastaria o cliente colocar a cabeça numa abertura da lona para se transformar de imediato em outra pessoa, ou para se transferir para outros espaços. Este recurso habitual do antigo estúdio Photo Royal Ltda constituía-se em fascínio e estranhamento para o narrador quando criança, a admirar a perícia do fotógrafo em criar, embora

${ }^{15}$ CALVINO, 1990, p. 99. 
imperfeitamente, outras virtuais possibilidades para o real, como na foto do Primo Casimiro a fingir que estava na selva africana:

([...] o primo Casimiro mudo) [...] introduziu o cachaço no buraco do telão da Photo Royal Ltda com jibóias e zebras, surgiu no retrato a matar uma onça mas o capacete colonial não coincidia com a cabeça, o corpo pintado agachava-se num tronco, uma das pernas gorda e a outra magrinha [...] havia uma rasgadura num lombo de zebra e pela rasgadura os trapezistas do circo, no buraco do segundo caçador, desocupado, um indiano de turbante equilibrava espadas no queixo ${ }^{16}$

Com este artifício - do fotógrafo fictício e do escritor real -, o referente da foto torna-se ambíguo, a realidade vacila, o imaginário se instala. $\mathrm{E}$, tal como nas fotografias, tudo no relato romanesco oscila entre o real e o imaginado, ou sonhado, ou confusamente lembrado - como já vimos em relação ao discurso do narrador principal dessa primeira parte do romance. As fotos doSr. Querubim metaforizam-se, pois, na própria escrita de Lobo Antunes, em dimensão metalingüística, tornada explícita em alguns momentos: "[...] ambos num tempo diferente em que se adivinhava/ (ou sou eu que imagino ou o António Lobo Antunes julgando que devo imaginar a fim de que o romance melhore) ${ }^{\prime \prime} .{ }^{17}$ E o que esta escrita autorreferente parece querer sinalizar é a inesgotável capacidade de as imagens gerarem imagens, de a linguagem gerar linguagem, evidenciando o processo de criação em que, a partir de um eixo casual, todo um possível universo se desdobra. Serviriam aqui, talvez, novamente, palavras de Ítalo Calvino sobre o seu próprio processo de construção literária, fundado na força da imagem:

\footnotetext{
${ }^{16}$ ANTUNES, 2004, p. 15.

${ }^{17}$ ANTUNES, 2004, p. 127.
} 
A primeira coisa que me vem à mente na idealização de um conto é, pois, uma imagem que por uma razão qualquer apresenta-se a mim carregada de significado, mesmo que eu não o saiba formular em termos discursivos ou conceituais. A partir do momento em que a imagem adquire uma certa nitidez em minha mente, ponho-me a desenvolvê-la numa história, ou melhor, são as próprias imagens que desenvolvem suas potencialidades implícitas, o conto que trazem dentro de si. Em torno de cada imagem escondemse outras, forma-se um campo de analogias, simetrias e contraposições. [...] Ao mesmo tempo, a escrita, a tradução em palavras, adquire cada vez mais importância; direi que a partir do momento em que começo a pôr o preto no branco, é a palavra escrita que conta: à busca de um equivalente da imagem visual se sucede o desenvolvimento coerente da imposição estilística inicial, até que pouco a pouco a escrita se torna a dona do campo. ${ }^{18}$

Tanto quanto no texto de Calvino, desta proliferação de imagens resulta, no texto de Lobo Antunes, uma escrita que corresponde plenamente ao princípio da visualidade, uma das propostas do escritor italiano para a literatura de nossa época:

Voltemos à problemática literária e perguntemo-nos como se forma o imaginário de uma época em que a literatura, já não mais se referindo a uma autoridade ou tradição que seria sua origem ou seu fim, visa antes à novidade, à originalidade, à invenção. Parece-me que nesta situação o problema da prioridade da imagem visual ou da expressão verbal (que é um pouco assim como o problema do ovo e da galinha) se inclina decididamente para a imagem visual. ${ }^{19}$

${ }^{18}$ CALVINO, 1990, p. 104-105.

${ }^{19}$ CALVINO, 1990, p. 102. 
No caso do romance aqui examinado (como, de resto, talvez, em toda a obra do autor), a abundância de imagens, a repetição exaustiva de certas imagens, a proliferação de detalhes, as enumerações, os incontáveis parênteses e cortes, as onomatopeias, a quase obsessão descritiva - realizada em movimentos de afirmação e de negação que tentam fixar (quase sempre sem sucesso) aquilo que é móvel na realidade - "tive a certeza que os melros contra o postigo do compartimento do fundo ou então o meu receio que os melros ou então a chuva mas como chuva se julho ou então os meus dentes ou então o sangue na minha cabeça, em mim todo" 20 -, tudo contribui para que o leitor, acompanhando o ziguezague da escrita em suas contínuas autocorreções, consiga visualizar mentalmente os espaços imagéticos do texto, fazendo, por sua vez, o movimento inverso ao do autor - da imagem verbal para a visual: todas as fotos observadas pelo narrador (refiro-me sempre ao narrador da primeira parte - "o pimpolho") podem ser, portanto, recompostas pela imaginação do leitor, até mesmo em suas imperfeições e nebulosidades: "ela no retrato de Tavira [...] e tu ao fundo, já não muito nova, de perfil a espessar-se / (os teus lábios diferentes, o teu pescoço diferente)/ numa cadeirinha de lona já não muito nova também [...]" ${ }^{21}$ Como lembra ainda Ítalo Calvino,

lemos por exemplo uma cena de romance ou a reportagem de um acontecimento num jornal e conforme a maior ou menor eficácia do texto somos levados a ver a cena como se esta se desenrolasse diante de nossos olhos, se não toda a cena, pelo menos fragmentos e detalhes que emergem do indistinto. $^{22}$

\footnotetext{
${ }^{20}$ ANTUNES, 2004, p. 86.

${ }^{21}$ ANTUNES, 2004, p. 181.

${ }^{22}$ CALVINO, 1990, p. 99.
} 
Por essas características, o texto de Lobo Antunes - dentro de sua especificidade muito peculiar - parece dialogar com algumas das importantes tendências da época contemporânea, em que, à sucessão tradicional de fatos encadeados, ao privilégio da intriga, contrapõe-se um discurso predominantemente descritivo, no qual a linguagem verbal constrói minuciosas e inquestionáveis imagens visuais. Neste sentido, vale citarmos passagem de um texto de Karl Erik Schollhammer que, referindose à pintura do período barroco, parece se adequar à análise de algumas das estratégias que sustentam a narrativa descritiva e visual de Eu hei-de amar uma pedra:

Os objetos, pequenos e grandes, são descritos com todos os detalhes e frequentemente apresentados de forma parcial, por fragmentos que correspondem a um determinado recorte empírico. A representação dá-se através da descrição minuciosa das superfícies iluminadas por fontes de luz pontuais, mostrando o mundo como um mapa recortado de forma arbitrária e sem pretensões narrativas, revelando a multiplicidade de pontos de vista e ressaltando especificidades na percepção de objetos particulares. ${ }^{23}$

O estudioso ressalta, em seguida, a importância histórica de tal paradigma estético, que acaba por precipitar uma mudança que se radicalizará justamente, no campo visual, com o surgimento da fotografia. Voltamos, assim, ao foco central desse romance de Lobo Antunes, a fotografia. Fictícia, ela assume, no texto, valor idêntico ao que tem no mundo empírico: registro da memória e desencadeadora do imaginário, a se oferecer, tanto à personagem quanto aos leitores, de forma ambígua - real e não real -, muitas vezes desfocada, incompleta, apagada, a sugerir a representação de

${ }^{23}$ SCHOLLHAMMER, 2007, p. 20-21. 
um mundo igualmente inapreensível em sua inteireza e a solicitar (da personagem e do leitor) um olhar repleto de estranheza e de questionamento:

O quinto retrato não foi tirado num estúdio dado perceberse que as árvores do fundo verdadeiras, [...] observando melhor apanha-se inclusive o movimento das copas dado que um bocadinho turvas como sempre acontece às fotografias no caso de uma das suas partes mexer, apanhase a vida derivado à

(exactamente como na vida)

nitidez diminuir e cada folha várias folhas sobrepostas e imprecisas $[\ldots]^{24}$

\section{Referências}

ANTUNES, António Lobo. Eu hei-de amar uma pedra. Rio de Janeiro: Objetiva, 2004.

ARNAULT, Ana Paula (Org.). Entrevistas com António Lobo Antunes - 1979-2007: confissões de um trapeiro. Coimbra: Almedina, 2008.

BARTHES, Roland. A câmara clara - notas sobre a fotografia. Trad. de Júlio Castañon Guimarães. Rio de Janeiro: Nova Fronteira, 1984.

CALVINO, Ítalo. Seis propostas para o próximo milênio. 2. ed. Trad. Ivo Barroso. São Paulo: Companhia das Letras, 1990.

SCHOLLHAMMER, Karl Erik. Além do visível: o olhar da literatura. Rio de Janeiro: 7Letras, 2007.

${ }^{24}$ ANTUNES, 2004, p. 93. 


\section{Resumo}

Este texto desenvolve reflexões em torno da presença de fotografias na primeira parte de Eu hei-de amar uma pedra, de António Lobo Antunes, buscando, sobretudo, perceber a dimensão metalingüística que se pode depreender do tratamento conferido pelo autor às imagens fotográficas que permeiam o discurso do principal narrador desta parte do romance.

\section{Abstract}

The present text develops some reflections on the presence of pictures in the first part of Antonio Lobo Antunes' I Shall Love a Stone, endeavoring, above all, to perceive the metalinguistic dimension which can be noticed from the treatment author assigns to the photographic images around this part of the novel's main narrator speech. 
